\title{
Screening and Preliminary Identification of Soil Potassium and Phosphorus-hydrolyzing Bacteria WP1-3
}

\author{
Zhao Yongmei $^{1 *}$, Wu Panpan ${ }^{1}$ \\ ${ }^{1}$ School of Biological and environment technology, Xi'an University, Xi'an 710065, China
}

\begin{abstract}
In order to screen the strains with Potassium and phosphorus-releasing bacteria from the soil, the potassium-dissolving medium was used for preliminary screening, and the transparent circle method was used for re-screening. The content of soluble potassium was determined by sodium tetraphenylborate method, and the content of phosphorus was determined by anticolorimetric method of molybdenum and antimony. The strains were identified by morphological, biochemical and molecular biology. The results showed that ten strains with potassium-solubilizing function were obtained by preliminary screening of potassium solubilizing medium. The re-screening by transparent circle method showed that WP1-3 strain had the strongest potassium-solubilizing ability, with D/d value of 1.33. WP1-3 strains of decomposition of soluble potassium content is $22.918 \mathrm{mg} / \mathrm{L}$, decompose inorganic phosphorus and organic phosphorus ability is $4.443 \mathrm{mg} / \mathrm{L}$ and $22.408 \mathrm{mg} / \mathrm{L}$, respectively. Identifying morphological and biochemical identification showed that WP1-3 strains was gram-negative bacteria, not produce spore, the nitrogen content of WP1-3 strain increased after detection and culture for $3 \mathrm{~d}$ and $7 \mathrm{~d}$ were 10.825 and $38.521 \mathrm{mg} / \mathrm{L}$. The $16 \mathrm{SrDNA}$ size was $1351 \mathrm{bp}$, the ribosomal database comparison showed that WP1-3 strain was 99.8\% similar to Rhizobium. Therefore, the WP1-3 strain belongs to the rhizobia genus.
\end{abstract}

\section{Introduction}

Potassium and phosphorus are important nutrient elements in plants and are biological nitrogen fixation must element, also are the key to promote the metabolism of plant growth. Potassium and phosphorus play an important role in regulating cell osmosis, material transport, promoting enzyme activation, promoting photosynthesis, improving carbon dioxide assimilation rate, promoting the synthesis and transport of substances in crops, and enhancing the resistance and tolerance of plants. Most of the potassium and phosphorus in soil are found in minerals such as silicate aluminates and apatite. Therefore, $95 \%$ of the potassium and phosphorus in soil cannot be directly absorbed by plants [1].

Potassium-hydrolyzing bacteria and phosphorushydrolyzing bacteria are a kind of bacteria isolated from soil that can decompose aluminosilicate and apatite minerals. As microbial fertilizers, they can decompose insoluble silicate aluminates such as potassium feldspar and apatite. They can promote the transformation of insoluble nutrients such as potassium, phosphorus and magnesium into soluble nutrients, and increase the content of available nutrients in soil, promote crop growth and development, improve crop yield [2]. Therefore, it is of great significance to separate the bacterial strains with potassium-releasing and phosphorus-releasing effects from soil and prepare microbial fertilizer to improve the utilization rate of potassium-phosphorus in soil. This paper studied the process of extraction and identification of potassium-releasing strains from soil, which provided reference for the development of new microbial fertilizer.

\section{Materials and Methods}

\subsection{Material}

\subsubsection{Sample materials}

Take $100 \mathrm{~g}$ of soil samples below $10 \mathrm{~cm}$ of surface near Xi'an University, mix samples well, dry them and stored.

\subsection{2 apparatus}

Fluorescence microscope (OLYMPUS-CX31), Super clean workbench, Electronic balance, Vertical automatic electric pressure steam sterilizer (LDZX-40II-type), Water-jacket heating constant temperature incubator (PYX-OHS-40x-0), Spectrophotometer, Digital constant temperature water bath oscillator (SHA-C) and others were used.

\subsection{Methods}

\subsubsection{Preparation of medium}

\footnotetext{
*Corresponding author: xazym1118@163.com
} 
Nutritional AGAR medium: peptone $10 \mathrm{~g}$, beef extract $3 \mathrm{~g}$, $\mathrm{NaCl} 5 \mathrm{~g}$, AGAR 15g, distilled water to $1000 \mathrm{~mL}$, pH7.27.4, sterilized and stored.

Potassium bacterial culture medium: glucose $10 \mathrm{~g}$,

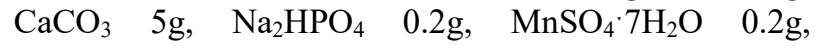
$\mathrm{CaSO}_{4} \cdot 2 \mathrm{H}_{2} \mathrm{O} 0.2 \mathrm{~g}, \mathrm{NaCl} 0.2 \mathrm{~g}$, AGAR $18 \mathrm{~g}$, potassium feldspar $10 \mathrm{~g}$, distilled water to $1000 \mathrm{~mL}$, $\mathrm{pH} 7.2$, sterilized and stored.

Potassium bacterial liquid medium: sucrose $0.75 \mathrm{~g}$, potassium feldspar $10 \mathrm{~g},\left(\mathrm{NH}_{4}\right)_{2} \mathrm{SO}_{4} 0.15 \mathrm{~g}, \mathrm{Na}_{2} \mathrm{HPO}_{4}$ $0.30 \mathrm{~g}$, distilled water to $1000 \mathrm{~mL}, \mathrm{pH} 7.2$, sterilized and stored.

Nitrogen-free liquid medium: sucrose $50 \mathrm{~g}, \mathrm{KH}_{2} \mathrm{PO}_{4}$ $2 \mathrm{~g}, \mathrm{MnSO}_{4} \cdot 7 \mathrm{H}_{2} \mathrm{O} \quad 0.5 \mathrm{~g}, \mathrm{FeCl}_{3} \quad 0.005 \mathrm{~g}, \mathrm{CaCO}_{3} \quad 0.1 \mathrm{~g}$, distilled water to $1000 \mathrm{~mL}, \mathrm{pH} 7.0-7.5$, sterilized and stored.

\subsubsection{Primary screening and purification of strains}

$10 \mathrm{~g}$ of soil samples were through a 100 -mesh sieve and put into $90 \mathrm{~mL}$ sterile water. After standing for $30 \mathrm{~min}$, they were shaken at $100 \mathrm{rpm}$ in a shaker at room temperature for $30 \mathrm{~min}$ to get a $10^{-1}$ times diluted suspension. $0.1 \mathrm{~mL}$ of $10^{-5}$ times diluted soil suspension was absorbed with sterile tubes and inoculated on potassium bacteria plate medium. After $5-7 \mathrm{~d}$ of culture at $30^{\circ} \mathrm{C}$, the single colonies with transparent circles were isolated and purified. After pure culture, the strains were transferred to nutrient AGAR medium, examined under microscope and numbered, then stored at $4^{\circ} \mathrm{C}$.

\subsubsection{Re-screening of potassium-hydrolyzing bacteria using transparent circle method}

The Primary screened strains were inoculated on potassium bacteria solid plate medium and cultured at $28^{\circ} \mathrm{C}$ for $5 \mathrm{~d}$. The potassium-lytic circle diameter $(\mathrm{D} / \mathrm{mm})$ and colony diameter $(\mathrm{d} / \mathrm{mm})$ of the strains producing transparent circles were measured with a ruler, and the ratio of colony diameter $(\mathrm{D} / \mathrm{d})$ was calculated to determine the potassium-lytic ability of the strains. The screened potassium-hydrolyzing bacteria with strong potassiumhydrolyzing ability were inoculated on nutrient AGAR medium and stored at $4{ }^{\circ} \mathrm{C}$.

\subsubsection{Soluble potassium content of strain using sodium tetraphenylboron method}

The strains were inoculated into the sterilized potassium bacterial liquid medium at the proportion of $3-6 \%$, and the same volume of sterile water was used as the control. The seed liquid was prepared by shaking culture for $5-7 \mathrm{~d}$ at $30^{\circ} \mathrm{C}$ and $180 \mathrm{rpm}$. The seed solution was centrifuged at $2000 \mathrm{rpm}$ for $20 \mathrm{~min}$ in order to discard the bacteria and residue. Then, $1.0 \mathrm{~mL}$ of formaldehyde-EDTA mask agent was added, shaken well, and $1.0 \mathrm{~mL}$ of sodium tetraphyborate solution was added accurately and quickly with a pipetet. After standing for $15 \mathrm{~min}$, it was shaken again. According to the standard curve drawn by sodium tetraphyborate method, the zero point of the instrument was adjusted with blank seed reference solution, colorimetric determination was carried out, and the absorbance of OD at $420 \mathrm{~nm}$ was recorded and the content was calculated.

\subsubsection{Determination of soluble phosphorus in strains using Mo-Sb antimony anticolorimetric method}

The strains were inoculated into $150 \mathrm{~mL}$ liquid phosphorus fermentation medium with 3-6\% inoculation amount, and cultured at $30^{\circ} \mathrm{C}$ and $180 \mathrm{rpm}$ for $5-7 \mathrm{~d}$, with blank seed liquid as the control. Molybdenum-Sb storage solution, molybdenum-Sb antichromogener and $5 \mathrm{mg} / \mathrm{L}$ phosphorus standard solution were prepared, and the phosphorus standard curve was drawn according to the molybdenum$\mathrm{Sb}$ antichromogener method. The soluble phosphorus content of strain was determined, and the blank seed reference solution was used to adjust the zero point of the instrument to conduct colorimetric determination. The absorbance of OD at 700nm was recorded and the content was calculated.

\subsubsection{Morphological identification and biochemical detection of WP1-3 strain}

After the preserved strains were activated by the culture medium of potassium-digesting bacteria, the morphological characteristics of their colonies were observed, and then the colonies were selected for Gram staining to observe the morphology of the bacteria, and the biochemical identification of potassium-digesting bacteria was carried out according to the common manual of common bacteria.

\subsubsection{SrDNA identification of strain WP1-3}

The identification process of the strain consisted of DNA extraction, PCR amplification, gel electrophoresis, purification and recovery, ligation, preparation of competent cells, transformation of ligation products, extraction and sequencing of plasmid, and comparison of 16SrDNA sequence on ribosome database after purification. The procedure was completed by Sangon Bioengineering Co., Ltd. (Shanghai). The reaction system of PCR was as follows: bacterial 16SrDNA universal primers 27 (AgTTTGATCMTGGCTCAG) and 1492 (GGTTACCTTGTTACGACTT) were selected to establish PCR amplification system for amplification. The PCR reaction system template (genomic DNA 20$50 \mathrm{ng} / \mathrm{nL})$ was $0.5 \mu \mathrm{L}, 10 \mathrm{x}$ buffer $2.5 \mu \mathrm{L}$, dNTP $(2.5 \mathrm{mM})$ $1 \mu \mathrm{L}$, enzyme $0.2 \mu \mathrm{L}, \mathrm{F}(10 \mu \mathrm{m}) 1 \mu \mathrm{L}, \mathrm{R}(10 \mu \mathrm{m}) 1 \mu \mathrm{L}$ and double steaming water to $25 \mu \mathrm{L}$. The amplification procedures were as follows: $94^{\circ} \mathrm{C}$ pre-denaturation for $4 \mathrm{~min}, 94^{\circ} \mathrm{C}$ denaturation for $45 \mathrm{~s}, 55^{\circ} \mathrm{C}$ annealing for $45 \mathrm{~s}$, $72{ }^{\circ} \mathrm{C}$ extension for $1 \mathrm{~min}, 30$ cycles in total, $72{ }^{\circ} \mathrm{C}$ extension for $10 \mathrm{~min}$, and the reaction products were terminated at $4{ }^{\circ} \mathrm{C}$. 


\subsubsection{Determination of nitrogen fixation capacity of WP1-3 strain}

The strain WP1-3 was cultured in a nitrogen-free liquid medium for $3 \mathrm{~d}$ and $7 \mathrm{~d}$, respectively. At the end, the nitrogen content in the medium was measured by microKjeldahl nitrogen determination method.

\section{Results and Analysis}

\subsection{Preliminary screening and purification of strain}

10 strains with strong potassium-hydrolyzing ability were screened out by culture on potassium releasing medium, which were WP1-1, WP1-2, WP1-3, WP2-1, WP2-2, WP3-3, WP3-2, WP4-1, WP4-2, etc.

\subsection{Re-screening results}

Transparent circle method is used to determine the releasing bacteria screening of soluble potassium circle diameter $(\mathrm{D} / \mathrm{mm})$ and colony diameter $(\mathrm{d} / \mathrm{mm})$, calculate the circle of soluble potassium and colony diameter ratio $(D / d)$. According to the ratio, the (D/ d) of WP1-3 strain was 1.33 , which was higher than that of other strains (Table 1). Therefore, the strain WP1-3 screened by the transparent circle method had the strongest potassiumhydrolyzing ability.

Table1. The potassium releasing ability of strains determined by transparent circle method

\begin{tabular}{|c|c|c|c|}
\hline strain & $\begin{array}{c}\text { Potassium-soluble } \\
\text { circle diameter } \\
(\mathbf{D} / \mathbf{m m})\end{array}$ & $\begin{array}{c}\text { Colony } \\
\text { diameter } \\
(\mathbf{d} / \mathbf{m m})\end{array}$ & $\mathbf{D} / \mathbf{d}$ \\
\hline WP 1-1 & 67 & 57 & 1.33 \\
\hline WP 1-2 & 61 & 50 & 1.22 \\
\hline WP 1-3 & 69 & 52 & 1.33 \\
\hline WP 2-1 & 70 & 57 & 1.23 \\
\hline WP 2-2 & 63 & 55 & 1.15 \\
\hline WP 2-3' & 68 & 57 & 1.19 \\
\hline WP 3-2 & 65 & 54 & 1.30 \\
\hline WP 3-3' & 63 & 51 & 1.24 \\
\hline WP 4-1 & 66 & 55 & 1.20 \\
\hline WP 4-2 & 65 & 53 & 1.21 \\
\hline
\end{tabular}

\subsection{Potassium minerals decomposed}

The standard potassium curve was $\mathrm{y}=0.0734 \mathrm{x}+0.002$, $\mathrm{R}^{2}=0.9822$. The determination results of potassium minerals decomposed by each strain are shown in Table 2 . WP1-3 strain can decompose potassium minerals, and the decomposed potassium content is $22.591 \mathrm{mg} / \mathrm{L}$ after comparing with the standard curve.
Table2. Results of potassium mineral decomposition

\begin{tabular}{|c|c|c|c|}
\hline strain & $\begin{array}{c}\text { Potassium } \\
\text { content } \\
\mathbf{m g} / \mathbf{L}\end{array}$ & strain & $\begin{array}{c}\text { Potassium } \\
\text { content } \\
\mathbf{m g} / \mathbf{L}\end{array}$ \\
\hline WP 1-1 & 12.632 & WP 2-3 & 18.325 \\
\hline WP 1-2 & 17.321 & WP 3-2 & 20.262 \\
\hline WP 1-3 & 22.591 & WP 3-3' & 16.183 \\
\hline WP 2-1 & 18.115 & WP 4-1 & 17.463 \\
\hline WP 2-2 & 16.921 & WP 4-2 & 13.586 \\
\hline
\end{tabular}

\subsection{Phosphorus decomposition ability}

The standard curves of inorganic phosphorus and organophosphorus were $\mathrm{y}=0.5731 \mathrm{x}, \mathrm{R}^{2}=0.9992$ and $\mathrm{y}=0.5417 \mathrm{x}, \quad \mathrm{R}^{2}=0.9958$, respectively. Determination results of decomposition phosphorus content of each strain are shown in Table 3. Compared with the standard curve, the degradation of inorganic phosphorus and organic phosphorus by WP1-3 strain reached $4.443 \mathrm{mg} / \mathrm{L}$ and $22.408 \mathrm{mg} / \mathrm{L}$.

Table3. Results of phosphorus decomposition

\begin{tabular}{|c|c|c|}
\hline strain & $\begin{array}{c}\text { inorganic phosphorus } \\
\text { content } \\
\mathbf{m g} / \mathbf{L}\end{array}$ & $\begin{array}{c}\text { organophosphor } \\
\text { us content } \\
\mathbf{m g} / \mathbf{L}\end{array}$ \\
\hline WP 1-1 & 0.284 & 5.563 \\
\hline WP 1-2 & 0.676 & 0.389 \\
\hline WP 1-3 & 4.443 & 22.408 \\
\hline WP 2-1 & 0.115 & 0.546 \\
\hline WP 2-2 & 0.228 & 0.687 \\
\hline WP 2-3 & 0.109 & 10.356 \\
\hline WP 3-2 & 3.147 & 1.549 \\
\hline WP 3-3 & 1.086 & 3.896 \\
\hline WP 4-1 & 0.834 & 8.408 \\
\hline WP 4-2 & 2.456 & 0.789 \\
\hline
\end{tabular}

\subsection{Morphological observation and biochemical detection of WP 1-3 strain}

According to its ability to dissolve potassium and phosphorus in soil, WP1-3 strain was screened out for morphological identification and biochemical detection. The results showed that WP1-3 colonies were round, rodshaped bacteria were colorless and transparent, with neat edges, moist and viscous, and elastic. The results of Gram staining showed that WP 1-3 colonies were Gramnegative bacteria.

\subsection{Identification of 16SrDNA strains of WP1-3}

The 16SrDNA sequence analysis and comparison results of strain WP1-3 showed that the fragment size of the product amplified by PCR was $1351 \mathrm{bp}$, and the 16SrDNA partial gene sequence obtained by sequencing (Seq ID 
No.3) had $99.8 \%$ homology with the related fragment sequence of rhizobia published in GenBank.

Based on the results of biochemical identification and 16SrDNA sequence analysis, the strain WP1-3 of the present invention was identified as Rhizobium sp.

\subsection{Nitrogen fixation ability of WP1-3 strain}

The nitrogen content in the medium was measured by microKjeldahl nitrogen determination method. The results showed (Table 4) that the nitrogen content of WP13 strain increased after detection and culture for $3 \mathrm{~d}$ and $7 \mathrm{~d}$.

Table4. Nitrogen content determination results

\begin{tabular}{|c|c|c|}
\hline strain & $\begin{array}{c}\text { 3d nitrogen } \\
\text { content } \\
\mathbf{m g} / \mathbf{L}\end{array}$ & $\begin{array}{c}\mathbf{7 d} \text { nitrogen } \\
\text { content } \\
\text { mg/L }\end{array}$ \\
\hline WP $1-3$ & 10.825 & 38.521 \\
\hline
\end{tabular}

\section{Conclusion and Discussions}

Microbial fertilizers are also known as biofertilizers, in which the effective microorganisms play a key role in the fertilizer effect [3]. It has the function of improving soil structure and adjusting microecological balance. The effective microorganisms can convert organic or inorganic minerals that plants cannot or are difficult to use into substances that can be used. It can improve soil fertility by increasing the soil effective N, P, K content, can enhance plant resistance by producing various antagonists and beneficial metabolites, so it affects plant hormone balance and promotes plant growth. It can also replace chemical fertilizers, pesticides and herbicides and reduce the amount of water used. At the same time, it can reduce soil pollution, improve the quality of crops, increase the content of protein and other aspects of the role [4]. However, due to the lack of in-depth research on potassium-hydrolyzing bacteria and phosphorushydrolyzing bacteria, the kinds of microbial fertilizer are not rich and many problems cannot be solved [5].

The WP1-1 strain purified in this study is a kind of rhizobia which can be used to decompose potassium and insoluble phosphorus in soil. The strain originated from the soil and was ecologically safe. It was selected from potassium feldspar as potassium source, as the effective microorganisms, during the growth and reproduction process, it can convert insoluble $\mathrm{K}$ in silicate aluminates into soluble components and increase the source of $\mathrm{P}$ in soil by promoting the decomposition of insoluble phosphorus. Moreover WP1-1 strain also has the function of nitrogen fixation, provide the required nitrogen metabolism of plant growth.

To sum up, there is still a lot of work to be done to develop new microbial fertilizers with high efficiency, environmental protection and multi-function. In this study, the potassium-hydrolyzing microorganisms collected from the soil of Xi'an were isolated, and their phosphorus digesting effect was studied by the anticolorimetric method of molybdenum and antimony. According to the biochemical characteristics and 16S rRNA gene sequence analysis, the taxonomic status of the strains was determined. This study plays an important role in the development of microbial fertilizer made from phosphorus and potassium-hydrolyzing bacteria.

\section{Acknowledgement}

Sponsored by Xi'an Science and Technology Plan Project (No 2019KJWL03)

\section{References}

1. M.Andrews, S.Hodge, J.A. Raven, Ann App Biol 157 (2010)

2. Illmer P. Schinner F. Soil Biol Biochem $(1992,24)$

3. Cordell D, Drangert JO, White S. Global Environmental Change 19 (2009)

4. Bin Wu,Zhen Yao Xia,Lin Lin Zhang,Shi Feng Guan,Ming Yi Li,Ke Yang,Wen Nian Xu. Advanced Materials Research 726 (2013)

5. U. Braun, W. Jehle. The Veterinary Journal,173 (2005) 